\title{
INNOVACIÓN TURÍSTICA: PERSPECTIVAS TEÓRICAS Y OBJETOS DE ESTUDIO
}

\author{
Antón Álvarez Sousa ${ }^{1}$ \\ Gustavo Rego Veiga \\ José Leira López \\ Alfonso Gomis Rodríguez \\ Rosa Caramés Valo \\ María José Andrade Suárez \\ Universidade da Coruña
}

\section{Resumen:}

En este artículo analizamos la innovación en el sector turístico desde el enfoque del sujetoorganización en cuanto actor de la innovación. Partimos del contexto en el que las organizaciones realizan acciones de innovación, indicando las grandes tendencias de innovación en el sector, el sistema nacional y local de innovación. Diferenciamos distintos tipos de innovación según la profundidad (radical o incremental) y según el factor de innovación (producto, proceso, mercado, organizacional) indicando la fuente, la motivación-efecto de la innovación y los obstáculos de la no introducción. Para cada innovación indicamos el tipo de organización más proclive a introducirla según el tamaño (grandes y pequeñas), el asentamiento (residentes y nuevos participantes) y las características de sus dirigentes.

Palabras clave: innovación turística, sistemas de innovación, tipos de innovación, organizaciones innovadoras, fuentes y motivaciones de innovación.

\section{Resumo: Innovación turística: perspectivas teóricas e obxectos de estudo}

Neste artigo analizamos a innovación no sector turístico dende o enfoque do suxeito organización en canto actor da innovación. Partimos do contexto en que as organizacións realizan accións de innovación e sinalamos as grandes tendencias de innovación no sector, o sistema nacional e local de innovación. Diferenciamos distintos tipos de innovación segundo a profundidade (radical ou incremental) e segundo o factor de innovación (produto, proceso, mercado, organización), con indicación da fonte, a motivación-efecto da innovación e os obstáculos da non-introdución. Para cada innovación sinalamos o tipo de organización máis proclive a introducila segundo o tamaño (grandes e pequenas), o asentamento (residentes e novos participantes) e as características dos seus dirixentes.

Palabras clave: innovación turística, sistemas de innovación, tipos de innovación, organizacións innovadoras, fontes e motivacións da innovación.

1 Antón Álvarez Sousa: sousa@udc.es, Gustavo Rego Veiga: gusrego@udc.es, José Leira López: leira@udc.es, Alfonso Gomis Rodríguez: agomis@udc.es, Rosa Caramés Valo: carames@udc.es, María José Andrade Suárez: mariquina716@hotmail.com 


\begin{abstract}
Tourism innovations: Theoretical perspectives and study objects In this article, we analyse innovation in the tourism industry focusing on the organisation-subject as an actor of innovation. Our point of departure is the context in which organisations perform innovation actions, and we indicate the major innovation trends in the industry, the national and local innovation system. We distinguish between different types of innovation on the basis of the depth (radical or incremental) and the innovation factor (product, process, market, organisational), specifying the source and the motivation-effect of the innovation and the obstacles arising from non-implementation. For each innovation, we specify the type of organisation most likely to implement it on the basis of the size (large and small), the settlement (residents and new participants) and the managers' characteristics.
\end{abstract}

Key words: tourism innovation, innovation systems, types of innovation, innovative organisations, sources and motivations of innovation.

\title{
1.- INTRODUCCIÓN. MARCO TEÓRICO
}

Siguiendo el Manual de Oslo. Guía para la recogida e interpretación de datos sobre innovación en su tercera edición, podemos diferenciar dos grandes formas de recogida de datos sobre la innovación (EUROSTAT y OCDE, 2006: 28): basándonos en el sujeto o en el objeto. La que se basa en el sujeto se centra en las actitudes y las actividades de las empresas en su conjunto y se realiza fundamentalmente mediante métodos cuantitativos y la técnica de encuesta. La que se basa en el objeto trata de innovaciones específicas y se emplea el estudio de casos.

En este artículo nos centraremos en el análisis de la innovación aplicada al sector turístico desde la perspectiva o enfoque del sujeto y haremos referencia a dos grandes tipos de sujetos que están presentes en el caso del turismo y que no afecta en la misma medida a otros sectores: organizaciones institucionales y organizaciones privadas o empresas. El producto turístico es el resultado de ambas y su estrategia es complementaria.

La innovación en el turismo se encuadra dentro del sector de servicios (Haudnes, 1998). El turismo es un sector que está sometido a un constante proceso de innovación, debido a que al ser unos servicios que tienen que proporcionar emociones nuevas a los turistas, si no innovan las actividades se convierten en rutinarias y dejan de proporcionar emociones y de ser visitadas (Plog, 1974, 1988). Cuando el turista visita un lugar ha de sentir emoción en cada uno de los componentes de su viaje -servicios- como en el producto turístico que se le ofrece en su conjunto.

Las innovaciones pueden ser de distinto tipo según el parámetro desde el que partamos. En base al grado pueden ser radicales o incrementales y según el factor de innovación pueden ser de producto, de proceso, de mercado u organizacionales.

En este artículo analizamos varios aspectos para entender el proceso de innovación de una organización como son:

- El contexto de las innovaciones refiriéndonos a los grandes cambios sociales en general que dan lugar a las innovaciones turísticas y a los sistemas de innovación que existen en un determinado territorio, y que condicionan la decisión de innovar de una organización según su ubicación. 
- Los distintos tipos de innovación, motivaciones para introducirlas, efectos y obstáculos en caso de no introducción. Las distintas teorías sobre los comportamientos organizacionales ante la innovación, todo ello referido al turismo.

- Finalmente concluiremos con un modelo de análisis de la innovación en las organizaciones turísticas, haciendo referencia específica a los temas que deben de ser objeto de estudio en un análisis aplicado de la innovación centrada en el sujeto.

Para la comprensión del modelo general de nuestro análisis nos remitimos al cuadro 1, en el que se puede ver que el centro lo ocupan los distintos tipos de innovación (producto, proceso, de mercado, organizacional) que tienen como finalidad la competitividad organizacional, a la que hay que sumar en la actualidad la innovación en el medio ambiente como algo impuesto a nivel legal-social y que tiene como finalidad la responsabilidad social corporativa. Estas innovaciones pueden estudiarse tanto desde la perspectiva del sujeto como del objeto. Pueden darse tanto en las organizaciones públicas como privadas. Han de entenderse dentro de un contexto de sistema local y nacional de innovación. Al mismo tiempo en el caso del turismo es necesario entender las grandes tendencias de la innovación que están relacionadas con la razón versus emoción, diferenciación versus unificación-bajo coste, sostenibilidad-autenticidad versus ludópolis.

Cuadro 1. Innovaciones y contexto innovador

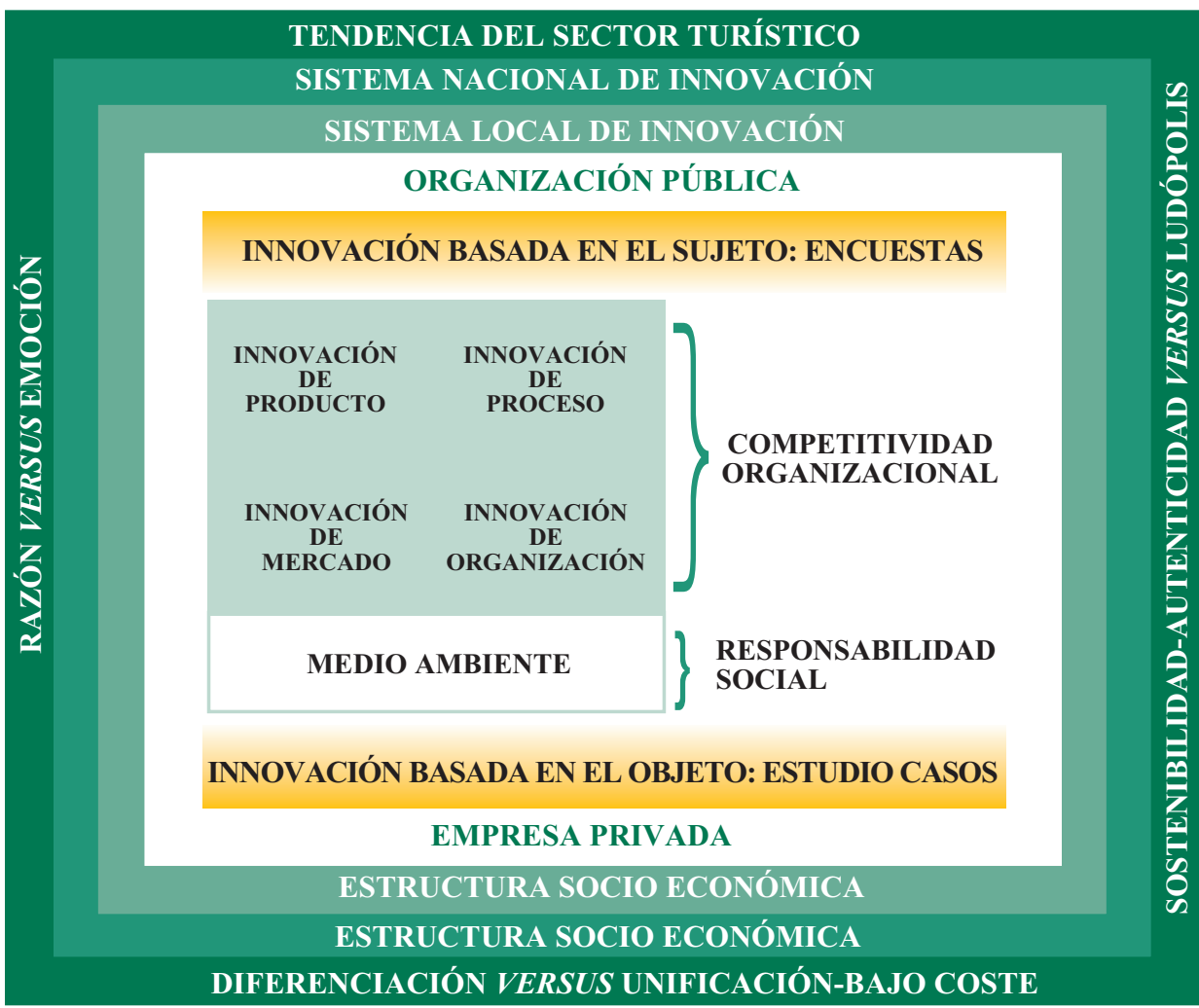




\section{2.- EL CONTEXTO DE LAS INNOVACIONES TURÍSTICAS}

\section{1.- LOS GRANDES CAMBIOS HISTÓRICOS QUE DIERON LUGAR A LAS INNOVACIONES TURÍSTICAS. LA SITUACIÓN ACTUAL}

Desde una perspectiva estructural podemos considerar que los comportamientos de las personas o de las organizaciones están condicionados por la estructura del sistema donde viven o prestan sus servicios. En el caso del turismo se dieron grandes cambiosinnovaciones a lo largo de la historia. Podemos así hablar de grandes etapas en el turismo coincidiendo con los grandes cambios en la estructura de la sociedad:

- En las sociedades medievales, basadas fundamentalmente en el poder de la iglesia y una concepción de la vida basada en el deber para con Dios, el turismo se puede asociar a las peregrinaciones en la búsqueda del encuentro para con un ser sobrenatural.

- Con el paso de las sociedades medievales basadas fundamentalmente en el poder de la iglesia a la formación de los grandes Estados basados en los poderes de la nobleza, el turismo también cambia de forma y es cuando surgen los viajes de la nobleza en la búsqueda del saber y la relación social

- Los cambios introducidos con las revoluciones Industrial y Francesa y el nuevo poder que toman los burgueses, lleva al turismo de la burguesía a la imitación de las funciones y las formas del turismo de la nobleza, pero ahora más extendido y relacionado con una nueva forma de vida, el comercio, el espionaje industrial, etc.

- Los grandes cambios introducidos por la técnica y la facilitación de los viajes a finales del siglo XIX y principios del siglo XX, conllevaron que los viajes se extendiesen a un grupo más amplio de población y afectaron además a la forma de organizarlos que ahora con los transportes colectivos ya puede ser un turismo en grupo

- La emergencia de la sociedad de consumo de masas después de la Segunda Guerra Mundial y posteriormente el desarrollo del Estado de Bienestar Social y los cambios introducidos en el estilo y la calidad de vida llevan al turismo de masas. Es la época del turismo industrial y del desarrollo concentrado en grandes polos y sectores, con los cuales se desarrollaron muchas zonas tomando el turismo como recurso fundamental.

- Las nuevas ideologías surgidas a finales del siglo XX y en concreto la sostenibilidad conlleva grandes cambios en el turismo y pasamos al turismo sostenible. Frente a esta ideología proclamada, en la práctica real también surgen los grandes centros de ocio y diversión que no tienen nada que ver con la sostenibilidad, sino con la diversión a tope: las ludópolis.

- Con el surgimiento de las nuevas tecnologías se cambia el turismo y la forma de organizarlo y para algunas personas parece que en el turismo todo está mediado por la racionalidad tecnológica. Sin embargo, frente a esta visión existen otras que resaltan el abandono de la racionalidad tecnológica en aras de las emociones. 
Nosotros consideramos que no son excluyentes sino que ambas confluyen en nuevas formas y prácticas de turismo.

- Todo esto hay que encuadrarlo dentro de una sociedad globalizada y el triunfo de la uniformidad, tarifas únicas, bajo coste. Pero además de globalización también está la glocalización y en el turismo a veces también se ama lo pequeño, lo irrepetible, lo específico, lo diverso, que lleva a la práctica de la diferenciación.

Analizar las innovaciones en el sector turístico pasa a su vez por analizar las grandes tendencias que se están siguiendo en el sector que nosotros representamos por tres grandes grupos de oposiciones: razón versus emoción; sostenibilidad versus ludópolis; diferenciación versus unificación-bajo coste.

\section{Razón versus emoción}

Por una parte parece que caminamos hacia un sistema donde la racionalidad tecnológica y de las TIC basada en codificaciones lo controla todo; sin embargo, frente a ello se alzan otras voces que dicen que cada vez caminamos más hacia un sistema donde lo que se valoran son las emociones y el invento de historias para producirlas.

En turismo la innovación basada en las TIC lo invadió todo, desde las personas que se motivan por viajar después de un viaje a través de la Red, hasta la información del lugar, la elección del medio de transporte, de alojamiento y las actividades a realizar. Desde esta perspectiva el turismo y los turistas estarían totalmente dominados por la racionalidad de las TIC que a través de la Red penetran en las emociones y el comportamiento de la población. En contra de esta postura, Jensen sostiene que frente a la racionalidad que culminó con la sociedad de la informática, surge una nueva sociedad en la que lo importante es saber fabricar productos basados en aspectos diferenciales que se pueden resumir en añadirle distinción a la calidad del proceso, saber contar historias en lugar de empaquetar sin más. "La conclusión es evidente -dice Jensen-: Historias y cuentos hablan directamente al corazón antes que la razón... En un siglo en que la sociedad está marcada por la ciencia y el racionalismo, por los análisis y el pragmatismo, viene el análisis simbólico a ocupar la posición más elevada de la sociedad -es aquí, precisamente, donde las emociones, las historias y las narrativas, los valores retornan al escenario. La sociedad del ensueño sugiere eso mismo. El mercado de sueños reemplazará gradualmente al mercado basado en la realidad de la información. El mercado de sensaciones eclipsará al mercado de productos tangibles" (Jensen, 1999: 3-4)

Podemos resumir los parámetros de la sociedad del ensueño frente a la sociedad de la información en base a una serie de oposiciones (ver cuadro 2), según las cuales si en la sociedad de la información se prima lo tangible (objetivo), en la sociedad del ensueño se priman las sensaciones (subjetivo); en la sociedad de la información se prima la mente y la inteligencia, en la sociedad del ensueño se prima el corazón; en la sociedad de la información se prima el logos, en la sociedad del ensueño se prima el mito; lo anterior lleva a que en la sociedad de la información se prima el discurso abstracto, en la sociedad del ensueño se priman las historias y lo ritual -mítico-; frente a la tecnología los valores; frente a la razón la sensación; frente al confort físico la satisfacción espiri- 
tual; resumiendo, por hablar en un término de moda, frente a la inteligencia racional la inteligencia emocional.

Cuadro 2. La sociedad del ensueño frente a la sociedad de la información

\begin{tabular}{ll} 
SOCIEDAD DE LA INFORMACIÓN & DREAM SOCIETY \\
\hline Inteligencia racional & Inteligencia emocional \\
\hline Confort físico & Confort espiritual \\
\hline Componente "logo" del ser humano & Componente "mito" del ser humano \\
\hline Discurso abstracto (en base numérica) & Historias, ritos \\
\hline Tecnología & Valores \\
\hline Tangible (objetivo) & Sensaciones (subjetivo) \\
\hline Mente, inteligencia & Corazón \\
\hline Muerte a los sentidos & Imperio de los sentidos \\
\hline
\end{tabular}

\section{Turismo sostenible-responsable versus ludópolis}

Hasta prácticamente la década de los noventa, no existió una filosofía explícita asumida por las autoridades ${ }^{2}$ y unas prácticas ordenadas y controladas que vigilasen por las funciones que estaba desempeñando el turismo, tanto para los turistas como para la sociedad receptora y en concreto para los objetos de atracción turística. A partir de la Cumbre de Río 92 y la Agenda 21, el concepto de desarrollo sostenible se extiende por todo el mundo. La concepción puramente economicista del desarrollo es abandonada para pasar, al menos como ideología proclamada, a una nueva concepción del desarrollo que, se dice, ha de incorporar cuatro ${ }^{3}$ dimensiones. Aunque analíticamente los presentemos de forma separada, el desarrollo sostenible es un proceso multidimensional, y unas dimensiones implican las otras, de tal modo que por ejemplo es imposible querer mantener la sostenibilidad del medioambiente natural si no se llevan a cabo a nivel social unas políticas de equidad para lo que se necesita la gobernabilidad (superestructura) adecuada.

- Social = equidad: Si se quiere conseguir una armonía de desarrollo sostenible, es necesario plantearse unos niveles mínimos de equidad en distintos ámbitos: a) Geográfico: a nivel global, entre lo que se denomina Norte-Sur o Primer Mundo y Tercer Mundo; entre los distintos Estados, entre las regiones, entre las localidades y entre lo rural y lo urbano y en general entre las zonas emisoras y receptoras de turismo; b) Estructural: Entre las distintas clases sociales, las distintas

2 Aunque en el ámbito intelectual la reflexión es anterior, ya con la teoría del crecimiento cero.

3 La mayor parte de los tratados e informes no incluyen la política: "El desarrollo sostenible ofrece a la Unión Europea una visión positiva a largo plazo de una sociedad más próspera y justa y que promete un medio ambiente más limpio, seguro y sano - una sociedad que permite una mayor calidad de vida, para nosotros, para nuestros hijos y para nuestros nietos. Para conseguirlo en la práctica es necesario que el crecimiento económico apoye al progreso social y respete el medio ambiente, que la política social sustente los resultados económicos y que la política ambiental sea rentable" (Comisión de las Comunidades Europeas, 2001: 2). 
razas y etnias, los distintos géneros y los grupos de edad y entre los distintos actores del sector turístico.

- Política = corresponsabilidad: Se refiere a la toma de decisiones, y las estructuras políticas deben de tener en cuenta tanto al sector privado como a la sociedad civil en general. Las decisiones de implantación de turismo y planes de desarrollo turístico han de contar con la participación de la población local y con los actores del sector. Aunque es a nivel nacional o supranacional donde se crea la estructura que dará lugar a los posteriores programas, los niveles local y regional se convierten en los foros de debate de necesidades y gestión de programas para llevar a cabo el desarrollo, y las instituciones políticas no pueden hacerlo al margen del sector privado y la sociedad civil, pues de lo contrario el programa de desarrollo sería no deseado y fracasaría.

- Económica = competitividad: A nivel económico lo que se le debe de pedir a cualquier proyecto turístico, aunque en los primeros momentos sea apoyado por el sector público, es que a la larga sea rentable económicamente y competitivo en este mercado global.

- Medioambiente (natural y cultural) = sostenibilidad-autenticidad: El medioambiente hace referencia a dos componentes fundamentales que son el natural y el cultural. Se parte de que los recursos naturales son renovables pero a una determinada velocidad, y por lo tanto la intervención sobre el medio debe de adaptarse a esta característica, no practicando intervenciones que lo dañen conduciendo a su degradación, a veces hasta tal punto que ya resulta imposible regenerarlos. En el caso del turismo cultural se trata de acondicionar los recursos para la visita de turistas sin que éstos pierdan su autenticidad (MacCannell, 1973, 1976, 1986; Cohen, 1979).

Este tipo de turismo y de turista responsable con la sostenibilidad, están latentes en una parte importante de las prácticas y programaciones turísticas actuales, pero se mezclan con otra postura que es todo lo contrario: la de espacios para que las personas puedan liberarse de su estrés y realizar todo tipo de actividades que deseen sin preocuparse por las repercusiones sociales y ecológicas de sus actos, ${ }^{4}$ y para ello se desarrollan cada vez más las ludópolis.

Con la emergencia de nuevas tecnologías y nuevas ideas sobre la vida y los valores, están surgiendo unas formas de turismo en la oferta y unas demandas de emociones que no se daban en el pasado. La mezcla de las nuevas tecnologías con diseño para experimentar nuevas emociones da lugar a las ludópolis. Por tal podemos entender los parques temáticos de segunda generación en los cuales el turista ya no es fundamentalmente un espectador, sino un actor en un escenario montado específicamente para disfrutar. Es lo que Sergio Molina denomina el posturismo y que tiene las siguientes características (Molina, 2006: 42-43):

1.- No es necesario desplazarse del lugar habitual donde se vive a otro, sino que se puede practicar en el mismo lugar donde se habita en espacios de megaatrac-

4 Lo que en otro lugar denominamos como turistas biotopo-oneomaníacos (Álvarez Sousa, 1994) 
ciones, con aventuras, recreación de ambientes de otros lugares de sociedades del pasado o del futuro, etc.

2.- No existe contacto con los individuos de las comunidades locales, sino que los turistas se encierran en un superatractivo, no interesados por la cultura local sino que recrean la aventura en un riesgo controlado por la alta tecnología

3.- Incluso el contacto con los espacios naturales puede ser resultado de un montaje basado en las nuevas tecnologías.

4.- Como corolario de los dos puntos anteriores, el espacio turístico no está determinado por los recursos naturales ni culturales disponibles en la zona, sino por el montaje.

5.- Mano de obra cualificada junto con la atención por otras personas sin cualificación alguna, prueba de la aplicación de maquinaria de alta tecnología que requiere elevada cualificación para el diseño y el montaje y que después puede ser atendido por personas sin ningún tipo de formación.

Si bien este tipo de atracciones pueden encontrarse en la actualidad en muchas ciudades que tienen sus centros como refugios para experiencias, especialmente en los shopping mal (Amándola, 2000), sin duda el lugar más típico es el de parques como los de Disney o zonas como Las Vegas. Disney está precisamente diseñado para convertir cada elemento en una experiencia distinta, tanto que sea un restaurante como un parque temático o un canal de televisión (Grover, 1993).

\section{Diversificación versus unificación-bajo coste}

Para simplificar podemos decir que la lógica de la diversificación de servicios y productos se encuentra dentro de una lógica de innovación glocal, frente a la que se alza en la actualidad la lógica de la innovación de valor-global, siendo el bajo coste una de sus manifestaciones. La diferencia entre ambos la centran Kim y Mauborgne (2000) en cinco dimensiones que son los supuestos aceptados en el sector, el enfoque estratégico, los clientes, ventajas y capacidades y oferta de productos y servicios (ver cuadro 3 ).

Cuadro 3. Diferencias entre las dos lógicas estratégicas: convencional e innovación de valor

\begin{tabular}{l|ll}
\multirow{2}{*}{$\begin{array}{l}\text { Cinco dimensiones } \\
\text { de la estrategia }\end{array}$} & \multicolumn{2}{c}{ LÓGICAS } \\
\cline { 2 - 3 } & $\begin{array}{l}\text { Innovación dentro de la lógica } \\
\text { convencional-glocal }\end{array}$ & De la innovación de valor \\
\hline $\begin{array}{l}\text { Los supuestos aceptados } \\
\text { en el sector }\end{array}$ & $\begin{array}{l}\text { Las condiciones y reglas del sector } \\
\text { se consideran como algo dadas, } \\
\text { inalterables. }\end{array}$ & $\begin{array}{l}\text { Es posible modificar las condicio- } \\
\text { nes del sector. }\end{array}$ \\
\hline
\end{tabular}

5 En el original sólo dice "Lógica convencional", nosotros le cambiamos por "innovación dentro de la lógica convencional-glocal", debido a que para nosotros también es innovación, lo que ocurre es que se trata de una innovación distinta a la del valor. Glocal en cuanto que en la diversificación turística una estrategia clave es aprovechar la identidad e imagen local para que no pueda ser imitado por otras zonas. 


\begin{tabular}{|c|c|c|}
\hline \multirow{2}{*}{$\begin{array}{l}\text { Cinco dimensiones } \\
\text { de la estrategia }\end{array}$} & \multicolumn{2}{|c|}{ LÓGICAS } \\
\hline & $\begin{array}{l}\text { Innovación dentro de la lógica } \\
\text { convencional-glocal }\end{array}$ & De la innovación de valor \\
\hline El enfoque estratégico & $\begin{array}{l}\text { Toda empresa debe buscar ventajas } \\
\text { competitivas. El objetivo es ganar a } \\
\text { la competencia }\end{array}$ & $\begin{array}{l}\text { Los competidores no son el punto } \\
\text { de referencia. Toda empresa debe } \\
\text { intentar ofrecer un salto cuantitati- } \\
\text { vo en el valor, a fin de dominar el } \\
\text { mercado }\end{array}$ \\
\hline Los clientes & $\begin{array}{l}\text { Toda empresa debe mantener y } \\
\text { aumentar su base de clientes } \\
\text { mediante una mayor segmentación } \\
\text { y personalización. Debe centrar su } \\
\text { atención en las características que } \\
\text { los clientes valoran de modo dife- } \\
\text { rente. }\end{array}$ & $\begin{array}{l}\text { El objetivo del innovador del valor } \\
\text { es la gran masa de compradores y } \\
\text { para lograrlo acepta perder algunos } \\
\text { de los clientes que ya tiene. Se } \\
\text { centra en los aspectos claves, valo- } \\
\text { rados en común por los clientes. }\end{array}$ \\
\hline Ventajas y capacidades & $\begin{array}{l}\text { Toda empresa debe de aprovechar al } \\
\text { máximo sus ventajas y capacidades }\end{array}$ & $\begin{array}{l}\text { Una empresa debe verse limitada } \\
\text { por lo que ya tiene. Se debe pre- } \\
\text { guntar: ¿qué haríamos si empezá- } \\
\text { semos ahora de cero? }\end{array}$ \\
\hline $\begin{array}{l}\text { Oferta de los productos } \\
\text { y servicios }\end{array}$ & $\begin{array}{l}\text { Existen unos límites tradicionales al } \\
\text { sector que determinan los productos } \\
\text { y servicios que puede ofrecer la } \\
\text { empresa. El objetivo es maximizar } \\
\text { el valor de la oferta. }\end{array}$ & $\begin{array}{l}\text { Un innovador del valor piensa en } \\
\text { términos de la solución total que } \\
\text { busca el cliente, aunque ello le } \\
\text { haga ir más allá de la oferta tradi- } \\
\text { cional del sector. }\end{array}$ \\
\hline
\end{tabular}

Fuente: Kim y Mauborgne, 2000: 212, con modificaciones nuestras ya indicadas.

Estos tres grandes pares de oposiciones constituyen el discurso postmoderno general sobre la innovación en turismo, y los grandes cambios que se están a realizar entran dentro de ellos.

\section{2.- SISTEMAS DE INNOVACIÓN: NACIONAL Y LOCAL}

La acción de innovación que una organización dedicada al turismo, pública o privada, puede desarrollar va a depender del contexto donde está ubicada, no teniendo las mismas probabilidades según que sea en un lugar donde existe un sistema nacionallocal de innovación o no. Pasamos a analizar cómo se mide un sistema nacional de innovación y el condicionamiento de un sistema local de innovación sobre un sujeto de innovación turística.

\section{Sistemas nacionales de innovación}

La Unión Europea preocupada por el empuje de la innovación en los distintos Estados miembros, propone varias medidas para que éstos apoyen la innovación a la vez que establece una serie de indicadores para medir el grado en que dichos Estados están 
apoyando la innovación. Si nosotros queremos comparar las posibilidades de innovación en un determinado Estado, podemos hacerlo midiendo el sistema de innovación que se da en comparación con otros Estados a la vez que analizando su evolución a lo largo del tiempo. Son los condicionantes que van a influir en que las distintas organizaciones en su conjunto lleven a cabo innovaciones (Comisión de las Comunidades Europeas, 2000). Para ello agrupa los distintos indicadores en cuatro grandes categorías que son los recursos humanos, la producción de nuevo conocimiento, la transmisión y aplicación del conocimiento, la financiación de la innovación, resultados y mercados. ${ }^{6}$

Recursos humanos, medidos en calidad y magnitud son factores determinantes para la producción de conocimiento innovador y su divulgación, existiendo dos niveles, por una parte el de los científicos que diseñan y por otra el de los técnicos encargados de llevarla a la práctica. Considera que se debe de medir: la proporción de titulados superiores en ciencia y tecnología entre todos los titulados de centros de enseñanza superior, el porcentaje de la población activa con educación superior, el porcentaje de empleo total en industria de media y alta tecnología, el porcentaje de empleo total en servicios de alta tecnología. ${ }^{7}$

La producción de nuevo conocimiento para medir la capacidad inventiva. Para ello propone los siguientes indicadores: el gasto público en $\mathrm{I}+\mathrm{D}$ en porcentaje del PIB, el gasto privado en $\mathrm{I}+\mathrm{D}$ en porcentaje del PIB, el número de solicitudes de patentes de alta tecnología por millón de habitantes.

Además de la producción del conocimiento, la innovación conlleva la trasmisión y aplicación del conocimiento, pues las organizaciones muchas veces adoptan los conocimientos que ya se produjeron en otros lugares y los adaptan. A veces incluso lo que se toma del exterior no es la innovación en sí, sino ideas y conocimientos que dan lugar a que se desarrolle la innovación. En esta categoría incluye los siguientes indicadores: el porcentaje de PYME industriales que realizan innovación interna, el porcentaje de PYME industriales que participan en proyectos de cooperación para la innovación, el gasto total en innovación en el sector industrial en porcentaje de volumen de negocio.

En la financiación de la innovación, resultados y mercados incluye seis indicadores que son el capital riesgo en empresas de tecnología en porcentaje del PIB, la capitalización de nuevos (nuevos, paralelos, secundarios) mercados en porcentaje del PIB, la cuota de ventas de innovaciones del mercado correspondiente al sector industrial, el porcentaje de utilizadores de Internet por 100 habitantes, la proporción de mercados de TIC en porcentaje del PIB $^{8}$ y los cambios en la proporción de producción total de la OCDE

\footnotetext{
6 En todo caso aclara que una comparación entre países basada en estos indicadores "puede ayudar a determinar los puntos fuertes y débiles de cada uno de ellos, en los que debería centrarse la acción pública y privada. No obstante, es importante tener presente que la innovación es una actividad compleja en la que interviene un amplio conjunto de factores. Un Cuadro de indicadores de innovación únicamente puede presentar un esbozo general de los puntos fuertes y débiles de las capacidades innovadoras de cada país" (Comisión de las Comunidades Europeas, 2000: 29).

7 En todo caso cuando lo aplicamos a un sector concreto como es en este caso el turismo, se deben de medir aquellos aspectos que más pueden resaltar el sector.

8 A nuestro entender estos dos últimos indicadores se deberían de incluir en otro apartado en el que se presentasen distintos aspectos relacionados con las TIC.
} 
en sectores de alta tecnología entre dos momentos de tiempo determinado, por ejemplo el último quinquenio del que tenemos datos.

\section{Sistemas locales de innovación}

El modelo de estudio de innovación nacional que acabamos de enunciar es válido para tener una gran visión de la ubicación espacio-temporal, pero las acciones se llevan a cabo en contextos muy concretos, en contextos locales, de ahí que sea necesario un modelo para analizar dicho sistema de innovación. Las posibilidades de que una organización lleve a cabo acciones de innovación y la repercusión que éstas tengan depende del contexto-medio en el que dicha organización desarrolla sus actividades. Un clásico en este tema es Porter, para quien la innovación en una organización depende de cuatro características del medio ambiente local que él denominó el modelo de diamante:

- Condiciones de factores: entre ellos se encuentran los recursos (en el caso del turismo aquellos materiales e inmateriales, naturales y culturales a partir de los cuales se pueden elaborar los recursos de atracción de turistas), la mano de obra cualificada (personas formadas en turismo o en actividades que puedan servir para realizar animación turística), capital (empresas decididas a invertir en servicios para elaborar los productos o administraciones decididas a acondicionar distinto tipo de infraestructuras que han de servir de apoyo a otros servicios para elaborar productos), centros de apoyo como instituciones educativas que lleven a la innovación, etc.

- Naturaleza de la demanda: la cual puede ser local, nacional, internacional, que se sienta atraída por la especificidad de los recursos que se le ofrecen. Los productos tienen que reflejar las necesidades turísticas de cada momento, las cuales varían a lo largo del tiempo. También se puede tener mucha fuerza para influir desde la oferta en el mercado, pero eso exige recursos y tiempo. Dicha influencia sólo se puede hacer por grandes compañías o destinos que invierten mucho, o bien por la asociación de varios sujetos que pueden llevar a una estrategia común (ejemplo las innovaciones de determinadas zonas en turismo rural a partir de la unión de pequeños inversores apoyados por la administración).

- Organizaciones relacionadas y de apoyo: en cualquier producto, pero en concreto en el turístico, las innovaciones pueden venir dadas porque alguno de los que fabrican recursos o prestan servicios introducen un elemento de innovación que repercute en todo el producto. A veces la innovación incluso puede venir dada por un componente externo pero que repercute en los propios elementos del producto, como por ejemplo las innovaciones de las TIC que repercutieron en la promoción, venta, distribución -se puede enviar vía electrónica un billete de un avión, la reserva de un hotel, la entrada a un concierto, etc.

- Estrategia, estructura y rivalidad de la empresa: la rivalidad es algo muy importante para la innovación. Al trabajar en un ambiente en el que existen otros competidores que están innovando, cualquier empresa turística o cualquier destino también tienen que innovar para así poder seguir ofreciendo algo atractivo, no 
pueden quedarse estancados, sino que necesitan mejorar de año en año para que el turista siempre encuentre algo nuevo e inesperado que le despierte emociones.

Nosotros vamos a presentar un modelo general de "contexto favorable a la innovación-necesidades locales de innovación" que consistiría en grandes puntos clave para analizar las posibilidades-necesidades locales de innovación y es el siguiente:

- La movilización-motivación de la población local: ${ }^{9}$ el primer paso para analizar las posibilidades de que triunfe un plan de innovación es que la población local tenga formación, motivación y se una para llevar a cabo las innovaciones. En un análisis del sistema local de innovación debemos de incluir aspectos como son: la formación de la población local, la motivación de la población local por hacer algo nuevo, el tipo de liderazgo. Para ello tenemos que consultar a los ciudadanos sobre su postura ante nuevos desafíos del desarrollo local, ante nuevas orientaciones que pueden ser de innovación incremental (mejorar aspectos existentes) o radicales (implantación de nuevos aspectos que ni siquiera había pensado en ellos), predisposición a participar en acciones de formación para las nuevas prácticas. ${ }^{10}$ También tenemos que analizar las vías de conexión entre sector público y privado, masas y élites, etc., con experiencia en foros de debate, asociaciones formales e informales para tratar temas. La innovación que se basa en la existencia de dicha formación, unión y foros locales, también ha de consistir en crear dicho capital allí donde no existe o mejorarlo y reorientarlo donde existe.

- Identidad e imagen de la zona: ${ }^{11}$ Las características específicas de una zona tienen que estar incorporadas a los productos turísticos. La labor de innovación va a conllevar precisamente la introducción de esa identidad para que sea algo específico, único, irrepetible y así todo el mundo que desee vivir dicha experiencia tenga que ir a esa zona. Pero ¿en qué se puede reflejar la identidad de una zona para innovar con ella e incorporarla a los productos turísticos? Podemos cifrar tanto elementos visibles como otros invisibles pero que están incorporados en la sociedad y la cultura local. Elementos visibles son por ejemplo el paisaje, el patrimonio natural y cultural, la arquitectura, la pintura, el idioma, la música, la literatura, el arte en general, los productos gastronómicos, etc. Invisibles son los conocimientos incorporados en los procedimientos, la forma de vivir - por ejemplo de marineros-, los valores sociales y las reglas de trato social, de saludo, de despedida, etc. En una propuesta de innovación en la identidad se deben de

\footnotetext{
9 En este apartado incluiremos lo que en otros lugares denominamos los capitales social y humano que condicionan la innovación al mismo tiempo que es necesario medir para analizar el impacto de la innovación sobre el desarrollo local (Álvarez Sousa, 2005).

10 Hablamos de ciudadanos en general, pero también podemos referenciarlo a veces al personal vinculado a un sector como es en este caso al turismo, tanto los que ya se dedican a prestar servicios, como otros posibles colectivos que sin prestarlos en la actualidad pueden prestar servicios que forman parte de un producto turístico (dígase jóvenes y posibles actos culturales, personas dedicadas al sector agrícola y posibilidades de prestar servicios para turismo rural, etc.)

11 Correspondería con lo que en otros lugares denominamos capital simbólico y que incluiría ambas, identidad e imagen (Álvarez Sousa, 2005).
} 
incluir actividades que reinventen símbolos, que resalten esos elementos visibles e invisibles que son propios, específicos e irrepetibles como son por ejemplo:

- La recogida de leyendas e historias típicas.

- Manifestaciones de exaltación de la cultura local, de su gastronomía, de su idioma, de sus tradiciones, de su forma de vestir, de vivir, de sus gentes, de sus colectivos. Para ello es necesario conocer bien el nivel de auto percepción local de su propia identidad.

- Cuidar a nivel de formación las vías de transmisión de conocimientos y procedimientos del pasado a las generaciones futuras, pues estos serán los elementos claves para la pervivencia. Si no existen vías de tránsito, la identidad muere.

Ahora bien, esta identidad tiene que estar recogida en una imagen que en la actualidad debe de estar cuidadosamente creada de modo que existan fuertes vínculos entre la imagen y los recursos y la identidad del territorio:

- En la publicidad se debe de resaltar bien el nombre del territorio

- Crear un logo que sea específico y que delimite bien su carácter en temas como las formas, el idioma, etc.

- La presencia de frases, refranes y eslóganes que sean típicos.

- Crear denominaciones de origen e intentar que en todas ellas se incluya referencia a esa imagen paraguas.

Esta presencia de la imagen debe de estar tanto en la reflexión previa como en la creación de publicidad, en la promoción y en el seguimiento de impacto de la promoción. Para ello tenemos que realizarnos preguntas sobre la identidad e imagen que se está difundiendo y la que es posible difundir innovando para favorecer los productos turísticos.

- El medio natural y cultural: la innovación depende de la posesión de recursos culturales y naturales y de su gestión junto con la ordenación del territorio ${ }^{12}$. Las actividades que realiza el turista están relacionadas con una serie de recursos y su gestión. Aunque en la actualidad se pueden montar escenarios totalmente artificiales para el turismo -el caso más ilustrativo son las ludópolis-, en general se suele valorar que una determinada zona tenga riqueza en recursos naturales y culturales y una experiencia positiva en la gestión y ordenación del territorio. Ante estas situaciones hay que plantearse una serie de preguntas relacionadas con el medio cultural, natural y ordenación del territorio como son:

- ¿Qué recursos culturales tenemos que ya estén acondicionados para la visita y el disfrute de los turistas?, ¿en qué sentido están acondicionados para que resalten los aspectos de identidad e imagen de las que hablamos en otro apartado?, es decir, ¿están acondicionados respetando su autenticidad o bien se expusieron a alteraciones que le llevaron a perder su sentido tradicional?

12 Es lo que en otros escritos denominamos el capital del medio ambiente natural y cultural. 
- ¿Qué recursos naturales tenemos que estén acondicionados para la visita y el disfrute de los turistas?, ¿están acondicionados bajo los principios de la sostenibilidad?, es decir, ¿el turismo sirvió para recuperarlos o se están degradando?

- Existe un plan de ordenación del territorio en el que se de cabida a las distintas inquietudes de la población dentro de una ordenación equilibrada de los recursos y los intereses conservando la armonía espacial.

- ¿Qué nivel de conciencia colectiva e individual existe respecto al medio?, ¿existen prácticas de las instituciones de distinto tipo, de las empresas, de los ciudadanos, colectivos sin ánimos de lucro que se dedican a velar por este tema?

- Las infraestructuras que sirven de base al turismo, con especial referencia a las comunicaciones y las nuevas tecnologías. ${ }^{13}$ Además de los recursos y de los servicios que forman un producto turístico, para poder desarrollarse el turismo en una zona se necesita que posea una serie de infraestructuras de acceso a la zona, de seguridad, de salud, etc. Cuanto más desarrolladas se encuentren dichas infraestructuras, mejor preparado estará el sistema local para la innovación en el turismo. Además de las infraestructuras indicadas, en la actualidad la innovación en el turismo pasa por la innovación en las nuevas tecnologías de la información y la comunicación (TIC).

- Grado de desarrollo del propio sector turístico, con su competitividad y acceso a mercados. Tenemos que analizar la demanda existente de los productos turísticos que se ofrecen en esa zona y las posibilidades de acceder a nuevos mercados para lo que se está ofreciendo y lo que se puede ofrecer y de competir con los productos que pueden ofrecer otras zonas.

Esto conlleva un análisis específico de los recursos y servicios con que cuenta ese territorio para crear productos turísticos que son demandados en ese momento, que posibilidades materiales y humanas existen para adaptarse a la lógica del mercado y qué posibilidades de cooperación existen entre los distintos agentes para llevarlas a la práctica. ${ }^{14}$

También conlleva un análisis de las estrategias que se están siguiendo en otros territorios (elaboración de nuevos productos, estrategias de promoción, distribución, etc.) para así poder hacer frente a lo que está haciendo la competencia. En este punto también es muy importante la cultura de la calidad y la mejora, pues la competitividad ha de darse no sólo por la rebaja de precios y otras técnicas, sino también por la calidad que se ofrece.

Las acciones para innovar han de referirse a aspectos como los análisis del mercado que nos informen puntualmente y nos proporcionen nuevas ideas, la introducción de la cultura de calidad, la cooperación entre los agentes del territorio para acceder conjuntamente a nuevos mercados, la colaboración con otras zonas -fortalecimiento de cooperación territorial- para garantizar competitividades conjuntas, etc.

13 Es lo que en otros lugares hemos denominado capital infraestructural.

14 En este sentido son muy importantes otros aspectos de los que hablamos en párrafos anteriores como la formación de la población (capital humano), la cooperación (capital social) y el desarrollo de la tecnología. 
Concluyendo sobre el sistema de innovación y las posibilidades de que las organizaciones públicas y privadas lleven a cabo acciones de innovación, tenemos que decir que en aquellas zonas ubicadas en Estados que tienen un elevado nivel de innovación en base a los indicadores presentados según el modelo de la UE y que a su vez se ubican en una localidad donde los factores indicados para el sistema local de innovación son favorables tanto en lo que respecta al capital humano su formación, motivación y unión; a la elevada identidad reflejada en una imagen bien diseñada; una ordenación del territorio adecuada con la conservación de los recursos naturales en base a la sostenibilidad y los culturales en base a la autenticidad; unas infraestructuras adecuadas; experiencia positiva en el sector, entonces lo más probable es que se desarrolle y se acepten fácilmente la introducción de innovaciones orientadas de modo positivo para el desarrollo del sector turístico.

\section{3.- TIPOS DE INNOVACIÓN Y ORGANIZACIONES MÁS PROCLIVES A INCORPORARLAS}

Existen distintos tipos de innovación que nosotros podemos referenciar al turismo y a las organizaciones turísticas. Las podemos diferenciar en base a la intensidad de la ruptura ocasionada y al aspecto que afectan.

\section{1.- INNOVACIONES SEGÚN LA INTENSIDAD DE LA RUPTURA OCASIONADA}

En base a este criterio podemos diferenciar entre innovaciones radicales e innovaciones incrementales. En todo caso, a veces las innovaciones incrementales acaban provocando innovaciones radicales.

- Innovaciones radicales (Leifer et al. 2000): Normalmente se considera una innovación como radical si el conocimiento para llevarla a cabo es muy diferente del conocimiento existente y hace obsoleto el conocimiento anterior. En términos de Kuhn (2006) podemos decir que es cuando se produce un cambio de paradigma y se pasa de un período científico a otro distinto, experimentándose así una revolución. A este tipo de innovaciones es a las que se refirió fundamentalmente Schumpeter. Considera este autor que una innovación es radical cuando se produce alguno de los siguientes supuestos:

- Introducción de un bien nuevo que hasta ese momento no era ofrecido a los consumidores

- La introducción de un nuevo método de producción o de comercialización que conlleva mejoras en la calidad

- Apertura de un nuevo mercado para un producto

- Nuevas fuentes de aprovisionamiento de materias que cambian el perfil de la organización

- Creación de una nueva organización, como por ejemplo un monopolio o la anulación de un monopolio existente (por suma o sustracción) 
- Innovaciones incrementales: ${ }^{15}$ Frente a la radical, el conocimiento para llevarla a cabo se basa en el conocimiento al uso, no existe un cambio de paradigma. Se refieren al añadido o la sustracción de ciertas características. Una parte muy importante de las innovaciones en el sector turístico son de este tipo y se refieren a pequeñas modificaciones en la funcionalidad del servicio propuesto.

Entre las innovaciones radicales y las incrementales existen grandes diferencias en cuanto a riesgo y medios financieros necesarios. Hay pensadores que consideran que la importancia de las invenciones incrementales es muy grande y en ellas se basan la mayoría de las invenciones. Sin embargo esto no resta poder a las invenciones radicales, que son necesarias para las incrementales. Aquí hay dos visiones distintas:

- Los que consideran que sin la existencia de cambios radicales previos (invenciones radicales previas) no es posible la existencia de invenciones incrementales

- Los que consideran que las invenciones radicales se producen por acumulación de las incrementales (visión que emana de la evolución de los paradigmas de Kuhn)

Cuadro 4. Características de las innovaciones radicales e incrementales respecto al mercado según Hayes y Abernathy

\section{INNOVACIÓN INCREMENTAL INNOVACIÓN RADICAL}

La demanda del mercado es conocida y predecible Puede tener una demanda potencial elevada pero poco predecible. El riesgo de fracasar también es alto

El reconocimiento y la aceptación del mercado son rápidos Puede que la aceptación por parte del mercado sea lenta en un principio, pero se espera una reacción imitativa rápida de los competidores

Es fácilmente adaptable a las ventas existentes en el mercado y a la política de distribución
Puede exigir unas políticas de distribución, de marketing y ventas exclusivas para educar a los consumidores a causa de problemas especiales de garantía reparaciones

Encaja en la actual segmentación del mercado y en las políticas de producto
La demanda puede no coincidir con los segmentos del mercado establecidos, distorsionando el control de la empresa, y absorber el mercado de otros productos

Fuente: Hayes y Abernathy, 1980.

15 A veces también se habla de mejora continua. 


\section{2.- INNOVACIONES SEGÚN EL ASPECTO AL QUE AFECTAN}

En base a este factor podemos diferenciar cuatro grandes grupos de innovaciones: innovaciones de producto, de proceso, organizativas y de mercadotecnia

Las innovaciones de producto implican cambios en las características o el uso al cual se destinan los bienes o servicios. Esto también incluye la manera en que estos servicios se prestan medidos en eficiencia y rapidez. Si el bien o servicio es nuevo nos estamos refiriendo a una innovación radical. Si se trata de una mejora significativa nos referimos a una innovación incremental. Se puede referir tanto a las características técnicas como a los componentes y materiales o a otras características funcionales. Para llevar a cabo la creación o mejora de productos o servicios puede utilizar nuevos conocimientos o nuevas tecnologías.

Las innovaciones de proceso conllevan cambios significativos en los métodos de producción y distribución, o incluso si es radical un nuevo método. Esta innovación implica cambios en los materiales, las técnicas o recientemente en los programas informáticos. También se incluyen dentro de las innovaciones de proceso aquellas que conllevan un incremento de la calidad. Hablamos de la producción y la distribución en sentidos distintos: la producción son los cambios que incluyen nuevos equipos o técnicas para producir los bienes o servicios; la distribución son los cambios relacionados con la logística, los suministros y los productos finales, como por ejemplo la venta de productos o servicios turísticos por Internet u otros nuevos sistemas de reservas de las agencias de viajes.

Las innovaciones organizativas conllevan cambios en los métodos de organización y pueden afectar tanto al aspecto interno de la organización como a las relaciones externas. En lo que respecta a los cambios intraorganizativos se trata a veces de reducir personal y costes, de cambiar la formación-nuevos conocimientos y su difusión, la motivación de los trabajadores y con ello la productividad. También se trata otras veces de que así se esté más abierto a los clientes recibiendo estos mejor servicio, y otras de estar en contacto con otras organizaciones para trabajar en red, para aprovecharse de sus nuevos conocimientos, subvenciones, etc. A veces los cambios vienen dados por los cambios en la cadena de producción y comercialización, porque cambia la tecnología y con ello la estructura organizativa (ejemplo el paso de una agencia de viajes tradicional a una virtual; el paso de las líneas aéreas tradicionales a las de bajo coste, etc.). Otras veces los cambios implican un nuevo modelo de gestión basado por ejemplo en la calidad, ${ }^{16}$ que conlleva no sólo un nuevo departamento que se encarga de ese tema, sino una nueva forma de actuar en toda la organización y la relación con el contexto ${ }^{17}$. Innovaciones en la organización pueden llevar a dar más flexibilidad a los trabajadores, pero aprovechando dicha flexibilidad para que hagan propuestas innovadoras a través de por ejemplo la creación de equipos formales e informales. Nuevas formas de producción también pueden conllevar nuevas formas de organización, como es el caso de sistemas de producción ‘justo a tiempo’ que puede llevar a atender a viajeros sin planificación previa, sino según se presentan; o al revés, fabricando en serie algo que antes se hacía al momento, como es el caso de determinados sistemas

16 Vemos así la relación entre distintos tipos de innovación, en este caso entre la de proceso y la organizativa. 17 Dígase por ejemplo la implantación de un enfoque de calidad EFQM. 
de cadenas de comida. A nivel externo se pueden adoptar nuevas formas de relación con la sociedad, con el entorno, con otras empresas, con instituciones públicas, etc.

Las innovaciones de mercadotecnia conllevan nuevos posicionamientos de productos, nueva identidad e imagen, cambios en la promoción y la comercialización. El objetivo inmediato puede ser el satisfacer mejor a los consumidores, el abrir nuevos mercados, etc. Para que exista realmente innovación en la mercadotecnia la organización debe de introducir instrumentos de promoción y comercialización que no utilizaba antes, y puede referirse tanto a productos que ya existían como a productos nuevos. En la actualidad es muy importante el cambio en el diseño, y por ejemplo un restaurante puede ofrecer el mismo producto, pero presentado de otro modo e incluso denominado de otro modo. A veces se trata incluso de hacer una presentación que conlleve el interés por un gusto distinto, un sabor distinto, etc. En lo relativo a la promoción se entiende que existe innovación si utiliza materiales o canales que antes no utilizaba, por ejemplo pasar a emplear documentales audiovisuales, proyectarlos en ferias, etc. También se incluye el lanzamiento de una nueva imagen de marca, un nuevo logo para renovar o cambiar la imagen, etc.; la promoción personalizada; las acciones de fidelización de clientes...

\section{3.- MODELOS TEÓRICOS PARA EL ANÁLISIS DE LA INNOVACIÓN EN LAS DISTINTAS ORGANIZACIONES}

\subsection{1.- Introducción}

Existen muchos modelos teóricos para explicar la posibilidad de introducir innovación en una organización y los distintos tipos de innovación según sea radical, incremental, etc. Pero no existe un modelo general que cruce los distintos tipos de innovación con los distintos tipos de organización. ${ }^{18}$ En lo que sigue vamos a presentar un modelo

18 Quizás el modelo más completo que pasa revisión a las distintas teorías de las innovaciones es el de Afuah (1999), que diferencia entre modelos estáticos y modelos dinámicos. Los modelos estáticos harían referencia a la innovación en un momento determinado y los modelos dinámicos a la trayectoria que toma la innovación, la cual tiene distintas fases. Nosotros consideramos que tales modelos no son contrapuestos, sino que podemos utilizar un modelo estático del tipo de innovación de que se trata y de la organización más específica para adoptarlo y al mismo tiempo introducir el aspecto dinámico para ver su evolución-trayectoria o ciclo de vida.

Entre los modelos estáticos tenemos distintas versiones tomando como referencia parámetros distintos que dan como resultado distintos tipos de innovaciones y de comportamientos organizacionales:

- Aquellos que se basan fundamentalmente en el tamaño de las organizaciones y analizan las diferencias ante la capacidad de introducir innovaciones según sean estas radicales o incrementales.

- Aquellos que se basan en las posibilidades o dificultades de introducir innovaciones incrementales o radicales según que las organizaciones sean residentes o nuevos participantes.

- Aquellos que combinan las capacidades técnicas y de mercado para extraer distintos tipos de innovación

- Aquellos que diferencian entre la innovación de los componentes y la innovación en la vinculación entre componentes

- Aquellos que se basan en como adoptar una innovación -por desarrollo interno, alianzas, adquisición educativa, etc.- según la matriz de familiaridad.

- Aquellos que se basan en analizar la cantidad y la calidad del nuevo conocimiento que se precisa

- Aquellos que se basan en la apropiabilidad y los archivos complementarios que necesita una innovación

- Aquellos que se basan en la opción estratégica de la organización para introducir una innovación, que puede ser ofensiva, defensiva, imitativa, etc. 
que a nuestro juicio incluye los distintos tipos de innovación expuestos en los distintos tipos de organizaciones y para ello combinamos los siguientes parámetros:

- El tipo de innovación según que se base fundamentalmente en el producto, en el proceso, en el mercado o en la organización

- Los distintos tipos de organización según:

- La antigüedad en el asentamiento, diferenciando entre las organizaciones residentes y los nuevos participantes.

- El tamaño, diferenciando entre las organizaciones grandes y las organizaciones pequeñas

En cada uno de los cruces resultantes podemos diferenciar la probabilidad de que se innove o no, y dentro de la innovación podemos diferenciar entre innovaciones en base a dos tipos de parámetros:

- La profundidad de la innovación, que puede ser radical o incremental

- El sentido, que puede estar basado en la diferenciación o en el valor

Para cada innovación resultante conviene diferenciar la fuente de la innovación, la motivación y el efecto que tiene y en caso de no adoptarla y estar interesado en ella cual es el obstáculo que condiciona la no adopción.

Finalmente presentamos el análisis de las características del personal que trabaja en la organización y sobre todo de los dirigentes, pues son estos los que toman las decisiones últimas sobre la introducción de innovaciones.

3.3.2.- Teorías sobre las organizaciones más o menos proclives a introducir distintos tipos de innovación

Cuadro 5. Tipos más proclives de innovación en las distintas organizaciones

\begin{tabular}{|c|c|c|c|c|c|c|c|}
\hline & & \multicolumn{5}{|c|}{ Factores de innovación } \\
\hline & & Tamaño organizacional & 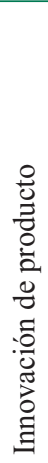 & 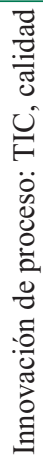 & 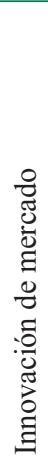 & 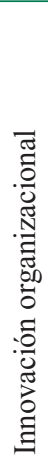 & 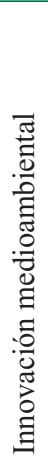 \\
\hline \multirow{4}{*}{ 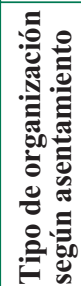 } & \multirow{2}{*}{$\begin{array}{l}\text { Organizaciones } \\
\text { residentes }\end{array}$} & Grandes organizaciones & 1 & 5 & 9 & 13 & 17 \\
\hline & & $\begin{array}{l}\text { Pequeñas } \\
\text { organizaciones }\end{array}$ & 2 & 6 & 10 & 14 & 18 \\
\hline & \multirow{2}{*}{$\begin{array}{l}\text { Organizaciones } \\
\text { nuevos } \\
\text { participantes }\end{array}$} & Grandes organizaciones & 3 & 7 & 11 & 15 & 19 \\
\hline & & $\begin{array}{l}\text { Pequeñas } \\
\text { organizaciones }\end{array}$ & 4 & 8 & 12 & 16 & 20 \\
\hline
\end{tabular}


Del cruce de los dos parámetros que dividen las organizaciones según el asentamiento (organizaciones residentes y nuevos participantes) y el tamaño (grandes y pequeñas organizaciones) con los distintos factores a innovar (innovación de producto, de proceso, de mercado, organizacional y medioambiental), resultan 20 escenarios distintos respecto a las posibilidades de innovar o no, a la innovación incremental o radical, y a la innovación basada en la diferenciación o en la estrategia de valor. A su vez tenemos que diferenciar entre las distintas fuentes de innovación, las motivaciones que llevan a innovar y los efectos de la innovación. En el caso de no innovar tenemos distinto tipo de obstáculos para la innovación.

En un artículo de estas dimensiones no podemos dar explicación detallada de cada uno de los posibles escenarios y su comportamiento, pasamos simplemente a dar una serie de directrices generales sobre el tipo de organizaciones que tienen mayor probabilidad de introducir innovaciones radicales o incrementales de cada uno de los factores de innovación

La innovación radical de producto es más probable que se tome por los nuevos participantes y en organizaciones tanto grandes como pequeñas. Ahora bien, conviene diferenciar entre radical en el sentido de que es algo nunca ofrecido y radical en el sentido de que es algo nuevo en una zona $u$ organización. Las innovaciones radicales en el sentido absoluto parece más lógico que las tomen empresas de una cierta dimensión para que sea posible difundirlas, pues si la organización es muy pequeña difícilmente se puede causar necesidad de consumo en el cliente y extenderse.

La innovación incremental de producto es más probable que la tomen las organizaciones residentes, y pueden ser las pequeñas organizaciones que se van adaptando poco a poco, o las grandes organizaciones que pueden tomar innovaciones incrementales consistentes por ejemplo en la diversificación y para lo que hacen un plan a cumplir en un determinado período.

Las innovaciones radicales de proceso, tanto si se trata de tecnología, como si se trata de calidad, parece más probable que las tomen las grandes organizaciones. Ahora bien, en este caso los residentes pueden ser los más favorables a tomar las innovaciones de calidad y los nuevos participantes la tecnológica, debido a que los cambios que conlleva una innovación radical tecnológica en una organización es muy costoso y puede implicar problemas de tiempo - cierre de los servicios de la organización por un tiempoademás de provocar cambios en la organización no deseados.

Los cambios incrementales en el proceso es más probable que los tomen las organizaciones residentes en lo que respecta a la tecnología y los nuevos participantes en lo que respecta a la calidad, pues es algo que hay que certificar poco a poco. Las pequeñas organizaciones tienen que adaptarse en la tecnología a lo que les dictan las grandes, pues muchas veces trabajan a su ritmo y para poder conectarse tienen que trabajar con tecnología compatible. La certificación de calidad en las pequeñas organizaciones a veces no se basa tanto en estándares generales, sino en sistemas más locales de calidad que le dan otro sentido distinto a las normas internacionales, pero que para el turista tienen gran importancia. 
Los cambios radicales en la innovación de mercado son asumidos fundamentalmente por las grandes organizaciones de nuevos participantes que quieren comenzar con una estrategia ofensiva, pero a veces también por las pequeñas organizaciones de nuevos participantes que buscan sistemas alternativos a los institucionalizados. Las organizaciones residentes que ya tienen una imagen de marca creada y una identidad es más probable que introduzcan cambios incrementales y sólo en casos muy estudiados pueden permitirse cambios radicales, pues es muy difícil volver a crear una identidad y una imagen reconocible.

En lo que respecta a los cambios organizacionales, las organizaciones establecidas es difícil que se planteen grandes cambios de sistema de organización, debido a que ello puede conllevar la retirada de muchos directivos y de otras personas. Sin embargo, las nuevas organizaciones tienen mayor probabilidad de establecer sistemas de gestión nuevos. Pongamos por caso líneas aéreas que ya tienen una cultura de la empresa y una forma de proceder, si sacan un nuevo producto al mercado por ejemplo de bajo coste, tienen mayor probabilidad de crear una organización nueva para gestionarlo que de cambiar la organización existente para adaptarse al nuevo producto.

En lo que respecta a la innovación del medio ambiente, se está pasando de una situación de control en la cual las pequeñas organizaciones a veces son las que más probabilidades tienen de adaptarse a las normativas. Su impacto, su producción de residuos, etc. les facilita la situación frente a las grandes organizaciones.

Pero parece como si estuviésemos hablando de innovaciones como algo deseado y buscado y a veces es algo casual o impuesto y en ese caso tenemos que diferenciar la situación de los distintos sujetos, pues lo que para uno puede ser una innovación radical para otro puede ser incremental o viceversa. Para ello es necesario tener en cuenta la cadena de valores agregados a la innovación. Según esta versión la innovación no puede limitarse a una organización concreta, sino que es necesario tener en cuenta toda la cadena de valores agregados de la innovación compuesta por los proveedores de materias primas para la elaboración de recursos o servicios turísticos, los fabricantes de dichos recursos o servicios, los TTOO que los ensamblan, los distribuidores, los clientes, otros innovadores complementarios, el ecosistema -ambiente socioeconómico y su nivel de desarrollo- de la organización y su ámbito de operación (ejemplo en el caso del turismo no sólo donde vende el producto -clientes- sino también del lugar de destino).

Así, la introducción de los fabricantes de componentes de productos turísticos en la red y la posibilidad de comercialización a través de ella, no sólo tiene implicaciones para dichos fabricantes, sino que también los tiene para los TTOO, para las agencias de viajes, para los turistas reales y potenciales, para las otras organizaciones similares. Tomemos como ejemplo de reflexión sobre el tema la venta de billetes electrónicos de las compañías aéreas, las reservas y ventas de habitaciones en hoteles, de entradas en distintos centros de animación, museos, conciertos, parques, etc. Esto nos llevará a un turismo mucho más a la carta, a cambiar las relaciones B-T, T$\mathrm{B}, \mathrm{B}-\mathrm{B}$, etc. 
Lo que esto implica además es que una innovación que puede ser incremental para un fabricante, puede ser radical para un proveedor o para un cliente o innovador complementario y al revés. Es decir, la innovación puede tener un efecto distinto en cada una de las etapas de la cadena de valores agregados de la innovación.

Por lo tanto, las implicaciones de una innovación que puede ser incremental o radical para un residente depende mucho también de las formas que dicha innovación tome en otros actores de la cadena de valores y de las implicaciones que tenga para ellos.

Como se puede ver en el esquema, incluso para algunos actores puede tener un efecto distinto: para algunos clientes-turistas, una innovación puede suponer un efecto incremental (cambiar algunas formas de su viaje y algunos servicios) y para otros radical: pasan a un comportamiento totalmente distinto al que hasta esos momentos tenían con el viaje, incluso puede ser el elemento desencadenante para viajar.

Cuadro 6. Cadena de valores agregados de la innovación y diferente posibilidad de efectos para los distintos actores turísticos

CADENA DE VALORES AGREGADOS DE LA INNOVACIÓN Y DIFERENTE POSIBILIDAD DE EFECTOS PARA LOS DISTINTOS ACTORES TURÍSTICOS

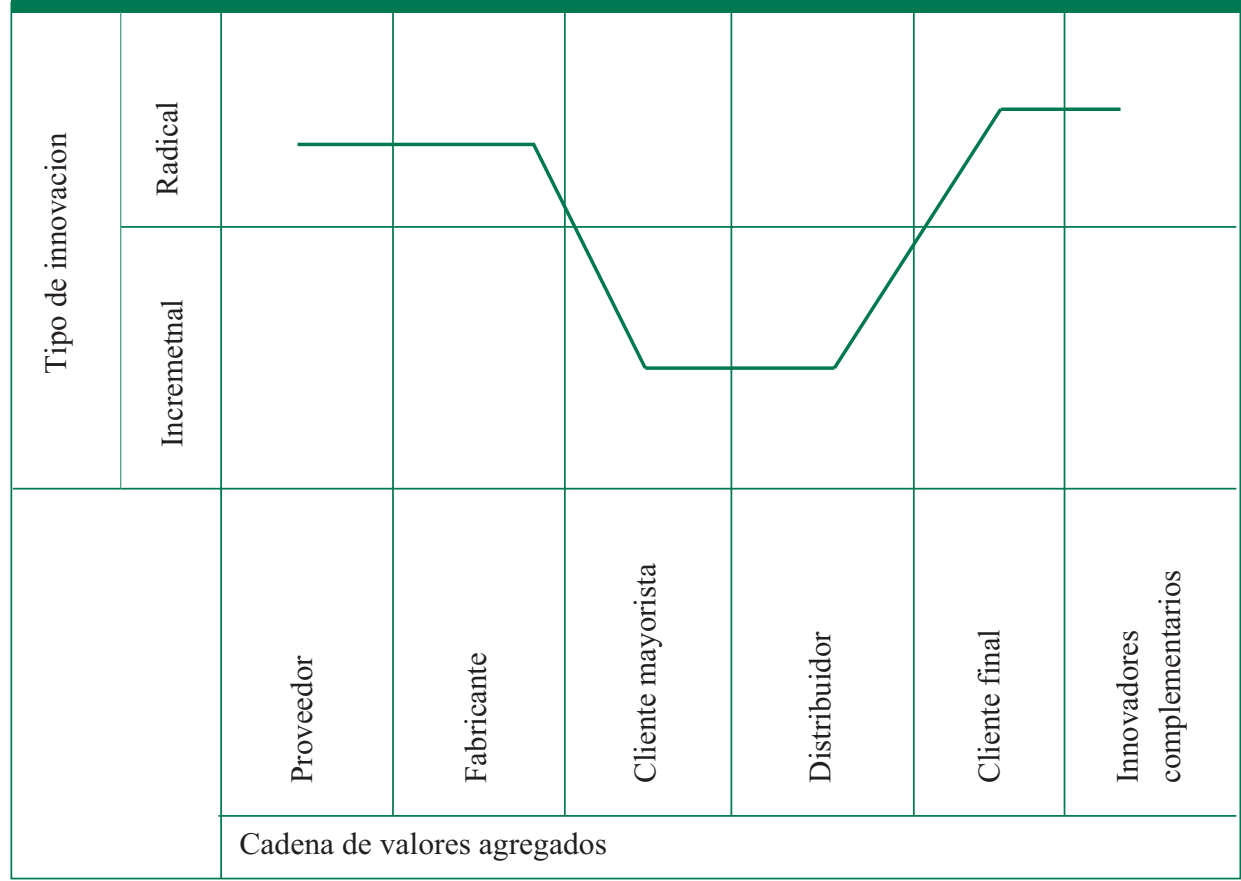

Fuente: Elaboración propia a partir de Afuah, A., La dinámica de la innovación organizacional, México, Oxford University Press, 1999, p. 28 


\section{4.- LA INNOVACIÓN: FUENTES, MOTIVACIONES, EFECTOS, OBSTÁCULOS}

En cada una de las innovaciones introducidas por una organización necesitamos saber una serie de datos relacionados con la fuente, motivaciones, efectos, y en el caso de la no introducción pero de estar interesado en ella cuáles fueron los obstáculos.

- Las fuentes de información que utiliza y formas de difusión

- Las motivaciones que puede tener una organización para innovar

- Los efectos que espera que tenga en la organización cada uno de los distintos tipos de innovación

- En el caso de las innovaciones que no introducen el motivo por el que no las introdujeron y los obstáculos con que se encuentran si las quieren introducir.

\section{Fuentes de innovación}

La innovación en las organizaciones puede venir dada por el interés explícito ${ }^{19} \mathrm{de}$ innovar o bien por una circunstancia casuística. En el caso del interés específico por innovar son varias las fuentes de donde se toman las ideas y podemos resumirlas en el proceso interno, las filtraciones de los competidores, proveedores y clientes y los centros de investigación de distinto tipo (universitarios, centros públicos y privados de investigación, etc.)

En el proceso interno de producción, todas las organizaciones están innovando constantemente al intentar ir adaptando su proceso de producción -innovación de proceso- a la mejor forma de producción posible y a lo que sale más barato y da mejores resultados. Además, algunas organizaciones cuentan con un departamento o unidad de innovación que es anterior a la fabricación y le va transfiriendo sus avances. A su vez, los departamentos encargados de la promoción y la comercialización también están siempre innovando al intentar que sus productos se diferencien de los de sus competidores y eso influya en la toma de decisión de los compradores.

Pero a veces las organizaciones no son totalmente originales en sus innovaciones, sino que las toman de los competidores. Incluso existe un importante sistema de espionaje que trata precisamente de conocer lo que hacen los otros para tomar los aspectos que sean importantes y asumibles. Freeman, Miles y Snow (1978) y otros diferencian distintas opciones estratégicas seguidas por las organizaciones para introducir las innovaciones. A partir de ellos, Afuah (1999) diferencia las siguientes:

- Estrategia ofensiva: es cuando una organización es la primera en introducir una innovación

- Estrategia defensiva: una organización espera que un competidor con una estrategia ofensiva introduzca la innovación y resuelva los posibles problemas. Después el de la estrategia defensiva la introduce corrigiendo los errores de sus predecesores. Ahora bien, intenta diferenciar sus productos y sobrepasar a la organización precursora.

19 Es lo que Eric von Hippel denomina fuentes funcionales (Von Hippel, 1988). 
- Estrategia imitativa: a diferencia de los anteriores no intenta diferenciar sus productos, tiende a imitar a la precursora y no intenta sobrepasarla. En todo caso la organización tiene independencia y acceso directo a materias primas y mercado.

- Estrategia dependiente: se acepta un papel de subordinado respecto a una organización más fuerte porque no tiene independencia de materias primas ni de mercado. Los cambios-innovaciones las introduce cuando se lo indica la organización de la cual depende

- Estrategia tradicional: apenas cambia los productos y cuando lo hace intenta no gastar demasiado en ello.

- Estrategia oportunista: busca satisfacer unas necesidades concretas del mercado que no han sido satisfechas por otros, buscando así un nicho en el mercado.

En varios casos, la fuente de innovación son los proveedores-innovadores complementarios y los clientes-demanda. Los proveedores-innovadores complementarios en cuanto que al comercializarse determinados componentes o herramientas técnicas para la fabricación de los productos o para prestar servicios y dejarse de servir las antiguas, la organización está obligada a innovar. Otras veces la fuente son los clientes que demandan unos productos o servicios con unas características que ya no tenían los antiguos y ello lleva a la innovación

La investigación que se realiza en las universidades o en centros-institutos públicos o privados puede ser de dos tipos: básica y aplicada. La aplicada ya está enfocada precisamente al progreso en el conocimiento aplicado y por lo tanto a la innovación. Pero incluso la básica que en principio no tiene como objetivo ningún producto concreto, al final termina siendo asumida por la innovación. Lo que ocurre es que muchas veces dicha investigación básica no cuenta como tal a la hora de declarar la fuente de la innovación debido a que no es una transferencia directa, pero indirectamente contribuye de forma muy importante, siendo un pilar fundamental del progreso.

Aunque suele existir una fuente fundamental, no existe total independencia entre todas ellas, sino que una innovación puede tener su origen último en una investigación básica, después seguirla desarrollando con la investigación aplicada, pasar a un departamento de una compañía que la adaptan, ser después tomado por otra organización, etc. Esto nos lleva a considerar que lo más importante es tener capacidad para integrar las ideas que provienen de distintas fuentes y saber integrarlas en la estructura y condiciones de una organización que quiere innovar.

Además de estas innovaciones que se producen de forma planificada, existe también un proceso de innovación que viene dado por el propio proceso de cambio social que va llevando a las organizaciones a actualizarse o morir, lo que hace que a veces la actualización provenga de forma secuencial y que apenas se den cuenta los propios directivos de que se está llevando a cabo la innovación. Así se pueden considerar desde los procesos de globalización actual que van llevando a cambios en todo el mundo, a cambios en los gustos y demandas de los consumidores, etc. Otras veces estos cambios se deben a ciertas discontinuidades tecnológicas que destruyen los procesos de producción y obligan a introducir otros nuevos, es lo que Schumpeter llama la destrucción creativa. 


\section{Motivaciones (objetivos) y efectos de la innovación}

Aunque los objetivos o motivaciones que mueven a innovar están relacionados con los efectos de la innovación, no son lo mismo. Los objetivos hacen referencia a las motivaciones que se tienen para innovar, y los efectos hacen referencia a los resultados de tal innovación. En todo caso podemos analizarlos conjuntamente, aunque después en el cuestionario se hagan preguntas que establezcan una cierta diferencia.

Las motivaciones y efectos pueden dividirse en varios tipos que nosotros hemos decidido agrupar en aquellos que tienen relación con la competitividad, con la presión de la demanda por nuevos servicios y productos para tener nuevas emociones, con la mejora de la imagen, con la ampliación e introducción en nuevos mercados, con la reducción de costes e incremento de beneficios, con las condiciones de trabajo y con el cumplimiento de la normativa legal y las demandas sociales.

En lo que respecta a la competitividad, toda organización tiene que ir cambiando productos que ya quedaban desfasados en el mercado y que las otras empresas de la competencia van introduciendo.

La demanda influye de forma muy importante en la oferta y en el caso del turismo al ser un sector que intenta despertar emociones en los consumidores, se trata de estar ofreciendo constantemente algo nuevo, distinto, incluso inesperado por los propios turistas. Un objetivo fundamental de toda empresa es incrementar la cuota de mercado e incluso introducirse en nuevos mercados, de ahí que sea necesario preguntarle también por este aspecto.

La motivación de la innovación en turismo puede centrarse a veces incluso de forma específica en darle un nuevo sentido a unos recursos que ya se están utilizando un nuevo imaginario, pues con ese nuevo sentido se pueden convertir en unos productos diferentes en cuanto que los recursos turísticos son fundamentalmente construcciones sociosimbólicas a través de un discurso. Otras veces no se trata de darle un nuevo sentido a los recursos para construir un nuevo producto, sino de cambiar-mejorar la imagen de la organización.

Otro motivo importante relacionado con la imagen es el de la calidad, en una sociedad donde desde hace unos años todo se evalúa desde la perspectiva de la calidad, existiendo calidad de distintos servicios, de recursos, de destinos, etc. que llevan a una cultura creciente de la calidad: donde ya no se trata de conformarse con un distintivo de calidad básico, sino caminar hacia una calidad de máximos.

La reducción de costes - a veces incluso se reducen materiales y energía- y el incremento de los ingresos con una mejora de los beneficios es sin duda el motivo último que puede mover a muchas empresas a la innovación, pero no siempre tiene por qué ser así, de modo que a veces en lugar de incrementar los beneficios la innovación puede afectar negativamente.

El objetivo también puede ser el mejorar las relaciones dentro de la organización (cambios en la comunicación interna) o con los clientes, proveedores, otras organizaciones similares, con la administración, etc. para de ese modo enraizarse más en la cultura del medio y que el medio asuma la cultura de la organización. 
En ciertos casos se innova por obligación para cumplir una determinada normativa que es obligatoria o recomendada pero que el no cumplirla estaría mal visto y se dañaría la imagen y las ventas de la empresa, como es el caso del medio ambiente, lo cual no está encaminado directamente a los beneficios de la empresa sino a la responsabilidad social corporativa.

A veces también se innova para ponerse al día en una determinada tecnología que de no hacerlo quedaríamos desfasados respecto al control que la tecnología ejerce sobre todas las organizaciones y que no podemos marginarnos de sus reglas de funcionamiento en una sociedad red (Castells, 2001). En este sentido es interesante incluir un apartado sobre la innovación tecnológica y en concreto las TIC que afectará de forma transversal a los cuatro tipos de innovación (producto, proceso, mercado, organizativa).

Cada una de estas motivaciones y de efectos, está presente de forma distinta en cada tipo de innovación, así las de competitividad afectan más bien al producto, la reducción de costes al proceso, la de imagen y demanda al mercado, la de relaciones internas y externas a la organizativa, etc. Esto es uno de los temas en los que debemos de centrarnos cuando se realicen estudios en el análisis de los datos.

\section{Obstáculos de la innovación}

Respecto a la no introducción de una determinada innovación puede deberse a que no se sintió la necesidad o a que no se planteó seriamente, pero también puede deberse a que se encontraron obstáculos para introducirla. Los obstáculos pueden ser de distinto tipo y algunos pesarán más en un tipo de innovación y otros en otros tipos; por lo tanto, se espera que algunos sean más propios de las innovaciones de producto, otros de las de proceso, otros de las organizativas y otros de las de mercadotecnia...

Los seis grandes bloques de obstáculos que diferenciamos pueden estar relacionados con los costes que tiene el introducirlos, con la ritualidad organizativa, con el potencial de conocimiento, con el mercado o con aspectos institucionales.

Los obstáculos basados en el coste pueden ser una percepción de riesgos excesivos, pero también un coste demasiado elevado para los fondos que se tienen y la falta de financiación externa. Es de esperar que este tipo de obstáculo afecte a todos los tipos de innovación, pero en menor medida a las organizativas.

Entre los relacionados con el potencial de conocimiento se encuentran la deficiente investigación, la falta de personal cualificado para aplicarla en la empresa, la falta de información sobre tecnología y mercados, la dificultad de encontrar socios que estén a la misma altura para las organizaciones que trabajan en red.

Entre los relacionados con el ritualismo organizacional se encuentra la respuesta de directivos que están bien asentados y prefieren seguir con los mismos fines y métodos, un personal con falta de motivación por lo nuevo y el esfuerzo que le pueda suponer $y$, a veces, unas estructuras organizativas rígidas que ofrecen gran resistencia a ser cambiadas al estar atadas incluso a estatutos y normas legales. Aunque estos inconvenientes pueden afectar a todo tipo de innovación, en el fondo están relacionadas con las innovaciones organizacionales. 
Entre los factores de mercado se encuentran la falta de una demanda que presione para introducir la innovación, incluso la dudosa demanda de los bienes o servicios resultantes de la innovación, o la existencia de otras empresas que pueden captar el mercado y no dejarnos a nosotros maniobra. Este tipo de obstáculos es más probable que afecten a las innovaciones de producto y de mercado.

Los factores institucionales pueden estar relacionados con unas reglamentaciones públicas que nos ponen problemas para adoptar determinadas innovaciones, bien de tipo puramente legal, bien de tipo medioambiental, bien de tipo fiscal, bien de propiedad, etc. Pueden afectar a todas las innovaciones pero más bien a las de producto seguidas de las de proceso.

\section{5.- EL LIDERAZGO ORGANIZACIONAL Y LAS INNOVACIONES}

Además de los otros factores condicionantes para que una determinada organización lleve a cabo acciones de innovación - contexto y tipo de organización-, también es muy importante el tipo de liderazgo que tiene dicha organización. En este sentido un peso muy importante para innovar lo tiene el modelo de la alta dirección que tenga la organización. A su vez, el modelo de alta dirección depende de la visión del mundo, la estructura mental que predomine en la organización, y esta visión depende de la lógica de la organización y de la estructura contextual en la que se inserte.

A veces la decisión de la innovación la pueden tomar agentes de nivel inferior, pero aún así la toman debido a que se insertan dentro de las creencias y la lógica de la alta dirección que al final es quien la acepta. En la literatura científica existen varios tipos de personas, algunas de las cuales se consideran más innovadoras que otras. Entre dichas teorías vamos a referirnos a la de Merton (1984: 231 y siguientes $)^{20}$ que nos da una explicación de los distintos tipos de adaptación a las metas culturales y los medios para alcanzarlas que se representan en el siguiente esquema y que dan lugar a cinco tipos de comportamientos: conformidad, innovación, ritualismo, retraimiento y rebelión.

\section{Tipología de los comportamientos según metas y medios institucionalizados}

\begin{tabular}{lcc} 
Modos de comportamiento & Medios institucionalizados & Metas culturales \\
\hline Conformidad & + & + \\
\hline Innovación & - & + \\
\hline Ritualismo & + & - \\
\hline Retraimiento & - & - \\
\hline Rebelión & - & - \\
& + & - \\
\hline
\end{tabular}

20 Otras tipologías son las de Myers-Briggs type indicator (MBTI) y la de Herrmann Brain Dominance Instrument (HBDI). El modelo MBTI emplea cuatro tipos de pares de atributos de donde resultan 16 tipos diferentes de personalidad. Los atributos son: extrovertido-introvertido, sensación-intuición, razonar-sentir, juzgarpercibir. Aunque existen varias posibilidades, las personas más creativas para la innovación podemos considerar que son los que combinan intuición con razonar y un poco introvertidos. 
La conformidad se da con las personas que están bien situadas en el sistema y satisfechos con la situación sin buscar otras situaciones diferentes aunque éstas le favorezcan, prefieren seguir como están.

Las personas innovadoras son aquellas que sin plantearse otras metas distintas a las institucionalizadas en las organizaciones, buscan medios alternativos para conseguirlas, y por lo tanto introducen cierta innovación.

Los ritualistas son personas que aunque se den cuenta de que pueden aspirar a otras metas superiores, prefieren seguir con los medios que siempre tuvieron, incluso a veces no optan por metas que pueden tener más ventajas que las que están siguiendo, pero están tan atados a los medios del pasado que prefieren seguir haciendo todo como siempre lo hicieron. Imaginémonos un hijo que le propone a un padre cambiar la gestión de un hotel e introducir reformas y su padre le contesta que se da cuenta de que ello es factible y de que con ello incrementarían su negocio, pero "siempre lo hicieron así y ahora no van a cambiar".

Retraimiento es el de aquellas personas que se abandonan con un mínimo para vivir y no se preocupan ni del progreso de las organizaciones en las que desempeñan su trabajo ni siquiera del progreso personal de ellas mismas.

Rebelión es el comportamiento de aquellas personas que están descontentas con el sistema tal como está o con las organizaciones en las que desempeñan sus funciones y proponen cambiar los fines que tienen y los medios y en su lugar proponen otros fines y otros medios distintos. Este tipo de personas serían las partidarias de cambios radicales, motivo por el que a veces no son deseadas por las organizaciones que ya están asentadas.

\section{4.- A MODO DE CONCLUSIÓN: PARA UN MODELO DE ANÁLISIS APLICA- DO DE LOS SUJETOS DE INNOVACIÓN}

A nivel práctico es interesante analizar los factores que condicionan la actividad innovadora de las organizaciones turísticas en sus distintas facetas o tipos de innovación: producto, proceso, organizativas y mercadotecnia (EUROSTAT y OCDE, 1986:23-24). A éstas hay que añadir la innovación relacionada con la introducción de las TIC, y el medio ambiente como obligación de responsabilidad social. Por ello es necesario diseñar un modelo que relacione los distintos tipos de innovaciones con las características de las organizaciones. De cada tipo de innovación interesa conocer la importancia que se le da, la introducción o no. En el caso de la introducción la motivación, la fuente, el impacto. En el caso de la no introducción el motivo-obstáculo y la probabilidad de que aún se introduzca.

Nuestra propuesta está basada en los modelos teóricos existentes -y de los que hemos dado cuenta anteriormente- y de los estudios realizados hasta estos momentos (EUROSTAT y OCDE, 2006; Hauknes 1998; OCDE, 2002; Sancho, 2004; Jacob et al. 2004; Alzua y Abad, 2005). Del modelo teórico precedente y de los estudios realizados se deduce que la actividad y la estrategia innovadora de las organizaciones turísticas está determinada por varios factores que son:

- Factores externos o medioambiente en el que está ubicada la organización turística, de tal modo que es distinto el comportamiento de una organización que está 
ubicada en un medio que cuenta con un sistema de innovación general de otra que está ubicada en un medio sin sistema de innovación.

- Factores endógenos de la propia organización que condicionan su predisposición a innovar. El tamaño de las organizaciones y la antigüedad de implantación son factores que condicionan su predisposición a innovar y a realizar innovaciones más incrementales o más radicales.

- Las características de la dirección de una organización son aspectos fundamentales, pues aquellas organizaciones que cuentan con líderes jóvenes, con alta formación y con unos valores que tienden hacia la innovación en lugar de tender hacia el ritualismo o el retraimiento (por hablar en términos de Merton), tienen mayor probabilidad de innovar que aquellas que están gestionadas por personas de edad más avanzada, con menor formación y con unos valores más conservadores.

Para medir el comportamiento predecible en los dirigentes de una organización y lo que es la dinámica de la organización (puede existir cierta coincidencia o no) proponemos realizar un análisis en base a la tipología de Merton explicada anteriormente y para ello proponemos sugerirle unas frases con las que ha de decirnos su grado de acuerdo. Dichas frases son las siguientes:

Puntúe del 1 al 10 (siendo 10, el grado de acuerdo máximo), las siguientes afirmaciones según se correspondan con la forma de actuar de usted y la lógica imperante en su organización.

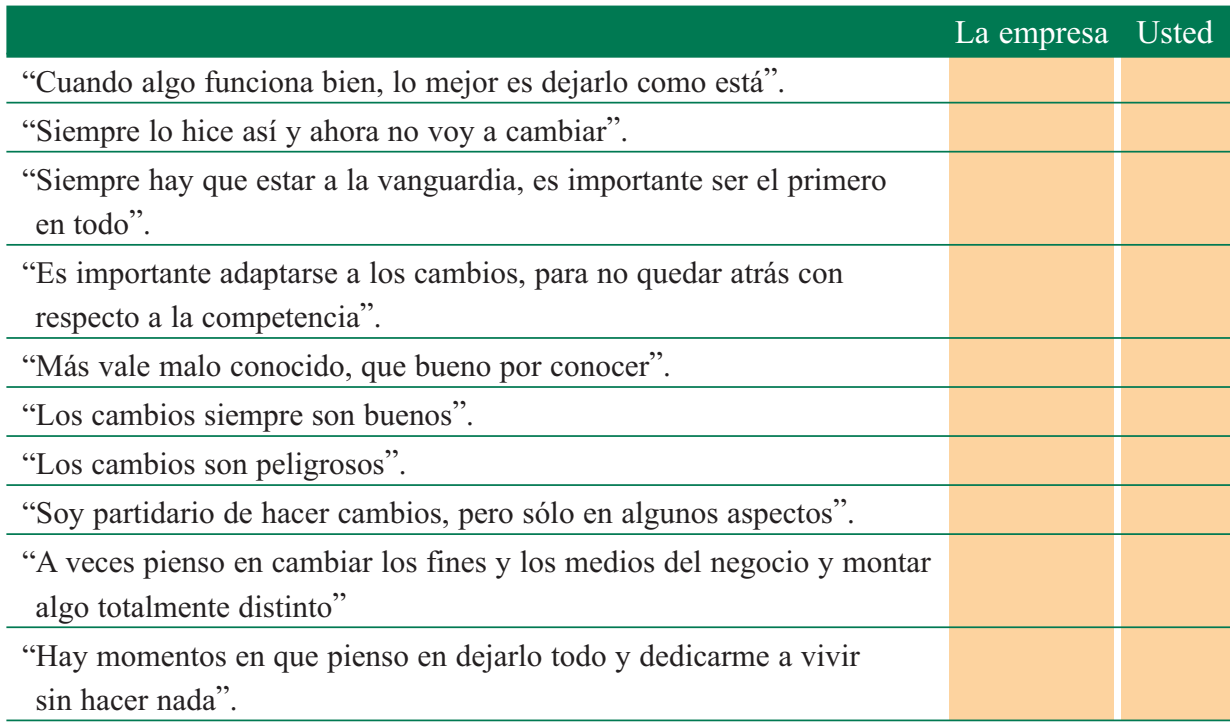

- La existencia de un plan de innovación y un plan de calidad dentro de la propia organización van a condicionar su comportamiento. Aunque existen algunas teo- 
rías que mantienen que el tener planes de calidad de mínimos, como puede ser por ejemplo la $\mathrm{Q}$ de calidad en el sector turístico pueden llevar a un cierto retraimiento al estar el establecimiento en la convicción de que con ello ya es suficiente, frente a otros que no la tienen y que innovan para mejorar, nosotros mantenemos la idea de partida de que los que tienen algún distintivo de calidad son más propensos a innovar, debido a que ya tienen experiencia en ello y además a que no quieren perder su "imagen" y quedarse atrás. En todo caso, esta variable será empleada de dos modos: como variable dependiente al explicar la calidad como una forma de innovación que va a depender de otras variables indicadas anteriormente, y como variable independiente al servir para explicar comportamientos generales y específicos de innovación de las organizaciones que la tienen frente a otras que no la tienen.

- Los distintos campos de innovación: aunque en principio se pueden distinguir distintos parámetros o campos de innovación, nosotros nos hemos centrado en los siguientes:

- Innovación en el producto o servicio que prestan: se tiene en cuenta el desarrollo de nuevos productos o servicios, la mejora de los existentes o bien otros complementarios.

- Innovación de proceso, en la que se ubica la introducción de nuevas tecnologías (aunque están presentes en los cinco tipos de innovación, aquí tienen un papel especial Innovación en las TIC: Internet y correo electrónico, Intranet, Extranet, página Web, servicio de conexión a los clientes), innovación en calidad: inocuidad de alimentos, normas ISO, Q de calidad, EFQM, sistemas para conocer demandas de clientes.

- Innovación en la promoción y la comercialización: se tiene en cuenta la promoción en general y la publicidad en concreto, la política de fidelización de clientes, nuevos mercados, mejora de canales de distribución y la introducción de modernos canales de comercialización.

- Innovación en la organización que puede ser interna y externa:

- Interna de la empresa: cambios en la estructura organizativa y de comunicación, desarrollo del área de RRHH, implantación de sistemas de vigilancia tecnológica y de mercado, implantación de sistemas de planificación estratégica. Innovación en la formación de directivos, de otros empleados, alfabetización en la cultura de la empresa, sistemas de formación on-line, en informática, en la rentabilización de innovaciones introducidas.

- Innovación en la seguridad, control y vigilancia: técnicas de predicción de escenarios de accidentes y riesgos, simulación de emergencias, evacuación, seguridad, inteligencia artificial.

- Innovación en las relaciones externas de la empresa: nuevas formas de relación con la administración y con otras empresas del contexto o del mismo sector en otras partes del mundo, nuevas colaboraciones con centros tecnológicos y de investigación-universitarios. 
- Innovación medioambiental: sistemas de ahorro de consumos, utilización de energías renovables, tratamiento de residuos, reducción de gases, mejora energética, depuración de aguas, vigilancia ambiental, concienciación clientes.

- Para todo ello es necesario saber sobre el plan de innovación existente o no y la fuente de financiación, así como la opinión sobre la autoevaluación donde se incluya tanto la visión sobre la importancia de las distintas innovación y la visión subjetiva comparativa con el contexto en materia de innovación.

- De cada una de las innovaciones concretas hay que saber la importancia que le dan y si disponen o no de ella. Entre los que disponen de ella hay que saber cual fue la motivación para introducirla, la fuente de información, las mejoras provocadas, cuando se implantó y cuando procede volver a innovar en ella. Los que no disponen de ella hay que saber si tienen interés en implantarla, los motivos por los que no la implantaron todavía y los obstáculos para su introducción.

\section{BIBLIOGRAFÍA}

Afuah, A. (1999): La dinámica de la innovación organizacional, México, Oxford University Press.

Álvarez Sousa, A. (1994): El ocio turístico en las sociedades industriales avanzadas, Barcelona, Bosch.

- (2005): "La contribución del turismo al desarrollo integral de las sociedades receptoras", Politica y Sociedad, Vol. 42, núm. 1: 57-84.

- (2007): "Desarrollo local e innovación. El sector turístico", en Manuel García Docampo (Ed.), Perspectivas teóricas del desarrollo local. A Coruña, Netbiblo, pp. 231-254.

Alzua, A. y Abad, M. (2005): Diagnóstico de innovación en el sector turístico de Euskadi, Tecnalia y Universidad de Deusto.

Amándola, G. (2000): La ciudad postmoderna, Madrid, Celeste Ediciones.

Castells, M. (2001): La era de la información. Economía, sociedad y cultura, Madrid, Alianza

Cohen, E. (1979): "Rethinking the sociology of tourism", Annals of Tourism Research, 6: $18-35$

COMISIÓN DE LAS COMUNIDADES EUROPEAS (2000): La innovación en una economía del conocimiento, $\operatorname{COM}(2000) 567$ final.

- (2001): Desarrollo sostenible en Europa para un mundo mejor: Estrategia de la Unión Europea para un desarrollo sostenible, $\operatorname{COM(2001)264~final~}$

EUROSTAT y OCDE (2006): Manual de Oslo. Guía para la recogida e interpretación de datos sobre innovación, Tragsa (original de 2005)

Grover, R. (1993): El toque mágico de Disney, México, McGraw-Hill.

Hall, B. (2005): "Innovation and Diffusion”, en J. Fagerberg, D. Mowery et al (eds.), The Oxford Handbook if Innovation. Oxford, Oxford University Press, capítulo 17. 
Haudnes, J. (1998): Services in Innovation, Innovation in Services, SI4S Final Report, STEP Group Oslo.

Hayes, R. H. y Abernathy, W. J. (1980): "Managing our way to economic decline", Harvard Business Review, Julio-agosto 1980, pp. 67-77

Jacob, M. ; Tintoré J. et al. (2004): Pautas de innovación en el sector turístico balear, Universitat de les Illes Balears e Instituto Mediterraneo de Estudios Avanzados.

Jensen, R. (1999): The Dream Society. How the Coming Shift from Information to Imagination Will Transform Your Business, New York, McGraw-Hill.

Kim, W. CH. y Mauborgne, R. (2000): “Innovación del valor. Lógica estratégica para un alto crecimiento de la empresa", Harvard Business Review. Creatividad e Innovación, Ediciones de Deusto, pp. 205-236.

Kuhn, T. (2006): La estructura de las revoluciones cientificas. Madrid, Fondo de Cultura Económica ( $3^{\text {a }}$ edición).

Lam, A. (2005): “Organizatinal Innovation”, en J. Fagerberg, D. Mowery et al. (eds.), The Oxford Handbook if Innovation. Oxford, Oxford University Press, capítulo 5. Leifer, R. et al. (2000): Radical innovation. Boston, Harvard Business School Press.

Maccanell, D. (1973): "Staged authenticity: arrangements of social space in tourist setting”, American Journal of Sociology, vol. 79, n 3, pp. 589-603.

- (1976): The tourist: a new theory of the leisure class, New York, Schocken Books.

- (1986): “Tourisme et identité culturelle”, Comunications, no 43, pp. 169-186.

Merton, R. K. (1984): Teoría y estructura sociales, México, Fondo de Cultura Económica.

Miles, R. E. y Snow, C. C. (1978): Organizacional Strategy, Structure, and Process, New York, McGraw-Hill.

Molina, S. (2006): El posturismo. Turismo y postmodernidad, México, Trillas.

Nelson, R. (1993): National Innovation Systems, Oxford, Oxford UP.

OCDE (2002): Frascati Manual, Proposed Standard Practice for Surveys Research and Experimental Development. Paris, OCDE.

Plog, S. (1974): "Why destination areas rise and fall in popularity", Cornell Hotel Restaurant and Administration Quaterly, 1974, pp. 55-58.

- (1988): "Undestanding psychographics in tourism resarch", en J. R. Ritchie y C.

Goeldner, Travel tourism and hospitality research. New York, Wiley.

Rogers, E.M. (1995): Diffusion of Innovations. The Free Press, New York (cuarta edición).

Rothwell, R. y Zegveld, W. (1985): Reindustrialization and Technology. London, Longman.

Sancho Pérez, A. (2004): Innovación, especialización, diversidad y competitividad en el sector turístico de la Comunidad Valenciana, Universidad de Valencia, http://www.uv.es/ sancho

Schumpeter, J. A. (1950): Capitalism, socialism and democracy, New York, Harper, $3^{\text {a }}$ Ed. Von Hippel, E. (1988): The sources of innovation, New York, Oxford University Press. 